\title{
Advanced Stirling Convertor (ASC) Development for NASA RPS
}

\author{
Wayne A. Wong ${ }^{1}$ and Scott Wilson ${ }^{2}$, \\ NASA Glenn Research Center, Cleveland, OH, 44135, USA \\ and \\ Josh Collins ${ }^{3}$ \\ Sunpower, Inc. Athens, OH, 45701, USA
}

\begin{abstract}
Sunpower's Advanced Stirling Convertor (ASC) initiated development under contract to the NASA Glenn Research Center (GRC) and after a series of successful demonstrations, the ASC began transitioning from a technology development project to flight development project. The ASC has very high power conversion efficiency making it attractive for future Radioisotope Power Systems (RPS) in order to make best use of the low plutonium-238 fuel inventory in the U.S. In recent years, the ASC became part of the NASA-Department of Energy Advanced Stirling Radioisotope Generator (ASRG) Integrated Project. Sunpower held two parallel contracts to produce ASC convertors, one with the Department of Energy/Lockheed Martin to produce the ASC-F flight convertors, and one with NASA GRC for the production of ASC-E3 engineering units, the initial units of which served as production pathfinders. The integrated ASC technical team successfully overcame various technical challenges that led to the completion and delivery of the first two pairs of flight-like ASC-E3 by 2013. However, in late Fall 2013, the DOE initiated termination of the Lockheed Martin ASRG flight development contract driven primarily by budget constraints. NASA continues to recognize the importance of high efficiency ASC power conversion for RPS and continues investment in the technology including the continuation of ASC-E3 production at Sunpower and the assembly of the ASRG Engineering Unit \#2. This paper provides a summary of ASC technical accomplishments, overview of tests at GRC, plans for continued ASC production at Sunpower, and status of Stirling technology development.
\end{abstract}

\section{Nomenclature}

ASC $\quad=$ Advanced Stirling Convertor

ASRG $\quad=$ Advanced Stirling Radioisotope Generator

DOE $\quad=$ Department of Energy

GPHS $\quad=$ General Purpose Heat Source

GRC $\quad=$ Glenn Research Center

RPS $\quad=$ Radioisotope Power System

\section{Introduction}

$\mathrm{T}$ HE 80-watt class Advanced Stirling Convertor (ASC) development was initiated by Sunpower, Inc. of Athens Ohio under contract to NASA Glenn Research Center (GRC) with the goal of achieving breakthrough efficiency, a key objective of the NASA Radioisotope Power Conversion Technology (RPCT) Project ${ }^{1}$ through which the contract was funded. The goal of RPCT was to develop next generation power conversion technologies that would provide improved performance over the systems that were being developed in the early 2000's, specifically the Multi-Mission Radioisotope Thermoelectric Generator (MMRTG) and the Stirling Radioisotope

\footnotetext{
${ }_{1}^{1}$ ASC Lead Engineering, Power Division, 21000 Brookpark Road, M.S. 301-2, Cleveland, OH, 44135.

${ }^{2}$ ASC Deputy Lead Engineer, Power Division, 21000 Brookpark Road, M.S. 301-2, Cleveland, OH, 44135.

${ }^{3}$ Project Manager, 1055 East State St, Suite D, Athens, OH.
} 
Generator (SRG-110). The Sunpower ASC contract was one of ten technology contracts awarded in 2003 that included a variety of conversion technologies and technology readiness levels that had the potential to enable RPS with high efficiency and low mass. The ASC technology provides high thermal-to-electric conversion efficiency reducing fuel requirements by a factor of four compared to thermoelectric systems, lowering system mass and enabling more non-solar NASA Science missions given the small plutonium-238 fuel inventory in the U.S.

The ASC is a free-piston Stirling engine integrated with a linear alternator that utilizes technologies from Sunpower's cryocoolers, Sunpower's 35 watt convertor developed under a NASA Small Business Innovative Research (SBIR) contract, along with advancements developed for the ASC that provided break-through performance. The technologies included hydrostatic gas bearings to allow non-contacting operation of the moving components, moving magnet alternator, high temperature heater head assembly utilizing nickel-based super-alloy, oxidation resistant high porosity regenerator, displacer planar spring, piston centering system, and very small clearances for the piston and displacer. The strategy to develop the ASC under the NASA contract included multiple builds, each of which addressed objectives to evolve the technology in preparation for eventual flight production. Each successive build includes design and processing changes to meet newly defined requirements, improve manufacturability, or enhance reliability. The ASC-1 demonstrated 38\% efficiency (88 $\mathrm{W}_{\mathrm{AC}}$ power output, $850^{\circ} \mathrm{C} \mathrm{T}_{\text {hot }}$ and $90^{\circ} \mathrm{C} \mathrm{T}_{\text {cold }}$ ). ${ }^{2}$ Early technology demonstrators (ASC-1, ASC-0, and ASC-1HS) continued to demonstrate high efficiency, small size, and low mass of the basic ASC design and allowed for the development of weld joints needed for hermetic sealing of the convertors. The early successful demonstrations provided clear indications of the advantages of the ASC over other technologies being developed under the RPCT Project and also convinced decision makers at NASA and DOE that the ASC should transition from technology development to flight development.

The next phase of ASC development necessary prior to flight adoption was the development of the ASC Engineering Units. In 2006, the decision was made to adopt the ASC technology as part of the Department of Energy and Lockheed Martin Advanced Stirling Radioisotope Generator (ASRG). Shown in Figure 1, the ASRG utilizes a pair of ASC convertors, each integrated with a General Purpose Heat Source (GPHS). In contrast to the earlier technology demonstration convertors that were designed for stand-alone laboratory operation, the ASC Engineer Unit (ASC-E) was developed specifically to be integrated onto the electrically heated ASRG Engineering Unit (EU) that required development of the generator interfaces and other design and process updates to meet the system requirements. In October 2007, GRC delivered two ASC-E convertors plus a spare on schedule to DOE/Lockheed Martin for integration onto the ASRG Engineering Unity (EU). The ASRG EU successfully completed a variety of system level demonstrations at Lockheed Martin followed by over 30,000 hours of extended operation at GRC.

While the ASC-E convertors represented a major advancement of the technology, two additional generations of developmental ASC convertors, the ASC-E2 and ASC-E3, were planned to prepare for flight development to address evolving flight requirements, identification of design improvements, and a need to continue to mature the Sunpower quality system for flight hardware production. The second engineering unit design, the ASC-E2 was built under a new formal Quality Management System at Sunpower, and would implement several reliability-driven or anticipated flight requirements-driven design changes. Specifically, the ASC-E2 required the development of a new heater head assembly design and manufacturing process making use of high temperature nickel superalloy 247-LC that would allow $850^{\circ} \mathrm{C}$ operation with long-life and reliability. GRC performed a variety of key technology support activities ${ }^{3}$ to mitigate risk including modeling and analysis, high temperature metallic tests, organic materials tests, convertor vibration tests, convertor continuous extended operation, and reliability analysis. Sunpower completed and delivered eight ASC-E2 convertors to GRC in 2010. To date, Sunpower has built and delivered 26 convertors under contract to GRC across

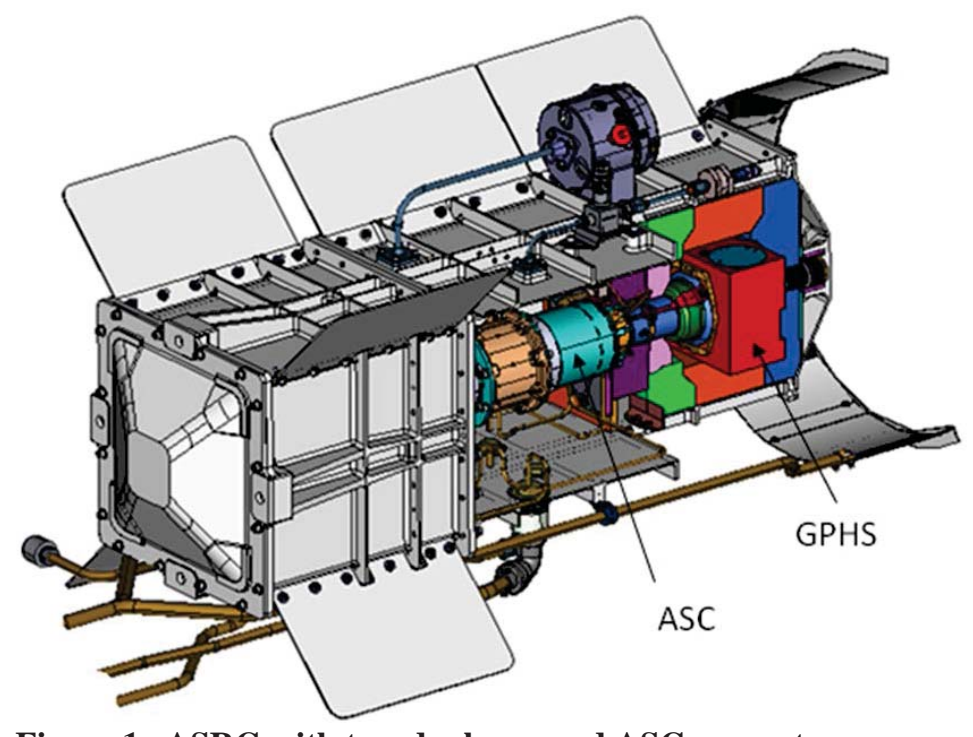

Figure 1. ASRG with two dual-opposed ASC convertors. 
several designs. The convertors are used for extended operation reliability testing, durability testing, and as support hardware for Lockheed Martin's controller development. The overall ASC design evolution strategy that was in place until Fall 2013 is illustrated in Figure 2.

\section{ASRG Integrated Flight Project}

Before the ASC-E3 engineering units were initiated under the NASA contract, Sunpower entered a parallel subcontract with DOE/Lockheed Martin for ASC-F flight development and production. A total of eight flight ASC-F units were planned with an initial pair to be used on the ASRG Qualification Unit, with two pairs used for two ASRG Flight Units, plus a spare pair of convertors. The circumstance motivated re-planning so that the ASC-E3, would be produced from the flight ASC-F specification and design documentation. The first two pairs of ASC-E3 became production pathfinders to demonstrate processes, identify and resolve any production issues and nonconformances, and reduce risk ahead of the flight ASC-F production steps. Additionally, this new strategy provided NASA with flight-like E3 convertors that could be used for extended operation and characterization tests to establish reliability of the flight design ${ }^{4}$. Further, In 2011 Sunpower relocated to a new facility that included a new clean room, designed specifically for ASC flight hardware production ${ }^{5}$. The ASC-E3 Pair 2 was the first hardware to be processed using the clean room, pathfinding new production procedures that addressed the flight cleanliness requirements. The last two pairs of ASC-E3 were intended to be "flight-like" and identical to the flight units with the exception of flight certification. General layout of the ASC flight design is shown in Figure 3.

The integrated project included two standing boards at the lower ASC production level, the Joint ASC Configuration Control Board (CCB), and the ASC Material Review Board (MRB). Both Boards had representatives from Lockheed Martin, DOE, and GRC with Sunpower personnel typically presenting to the boards. The Joint CCB had the responsibility to review and approve all ASC-F design documentation including drawings, process specifications, process documents, and test procedures. As discussed earlier, the ASC-E3 being produced for GRC uses the same ASC-F flight documentation thus the joint CCB was an effective means of ensuring all design and production updates are agreed upon by all parties. The MRB was actually made of a Flight ASC-F MRB and an E3 MRB that conducted reviews for the respective hardware at the same time, allowing mutual insight into nonconformances on both E3 and Flight builds, yet allowing disposition authority for hardware to remain with the appropriate parties for whom the hardware was being built.

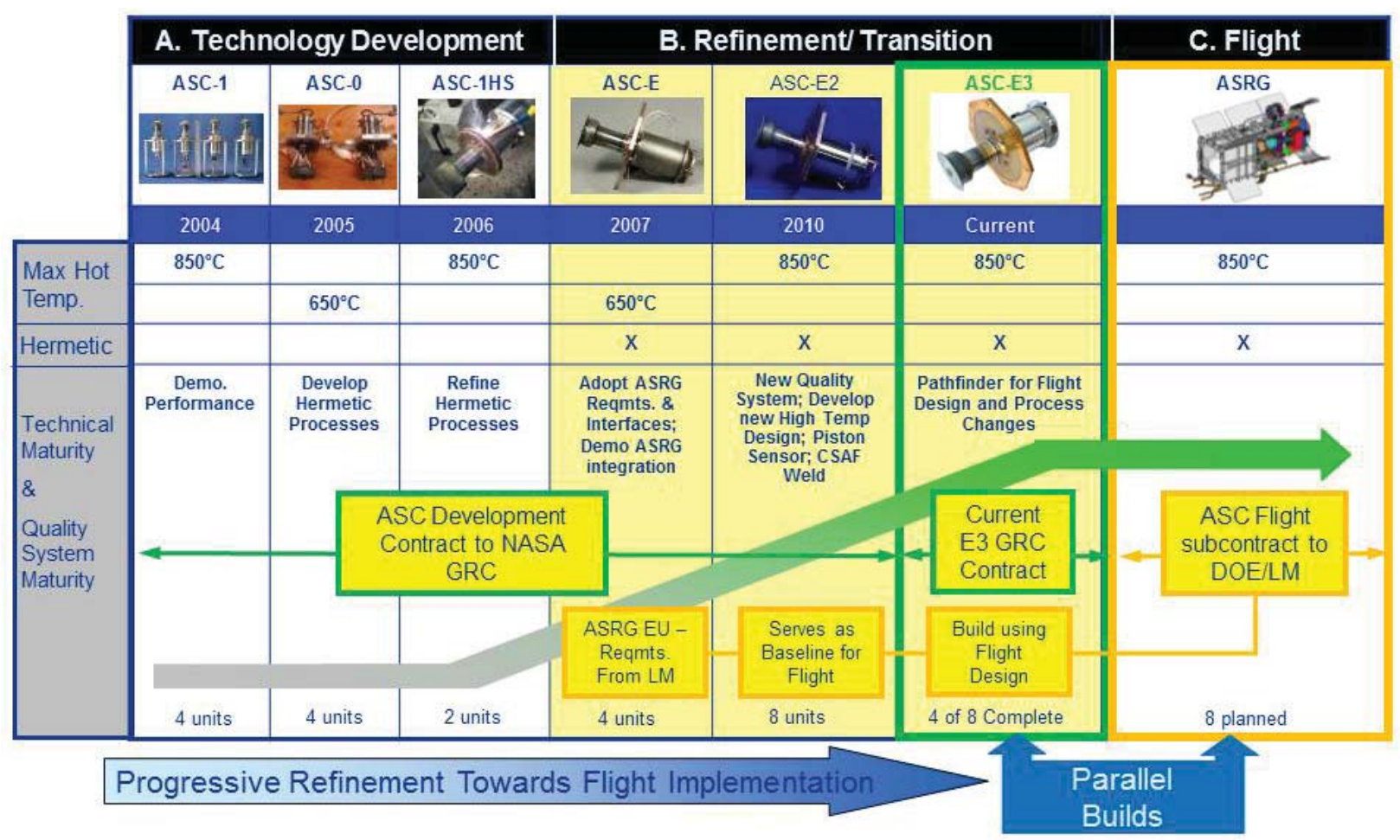

Figure 2. Previous ASC Technology Evolution Strategy - Current through October 2013 
To support the management of the ASRG Project, a continuous GRC technical presence at Sunpower was established to manage, monitor, and provide insight into the ASC-E3, ASC-F, and ancillary tasks. This value-added on-site activity was achieved through technical rotations of oneweek duration consisting of four individuals familiar with ASC design, production, and testing including the ASC lead engineer, Deputy ASC lead engineer, and two ASC cognizant test engineers that are responsible for ASC-E3 convertors after delivery. Similarly, Lockheed Martin also established a weekly rotation of onsite personnel at Sunpower with varying project roles including the Certified Product Engineer, Task Lead, and Quality Assurance lead. The GRC and LM personnel mix offered the desired skill set as Sunpower transitioned from the design phase and focused on ASC production and testing.

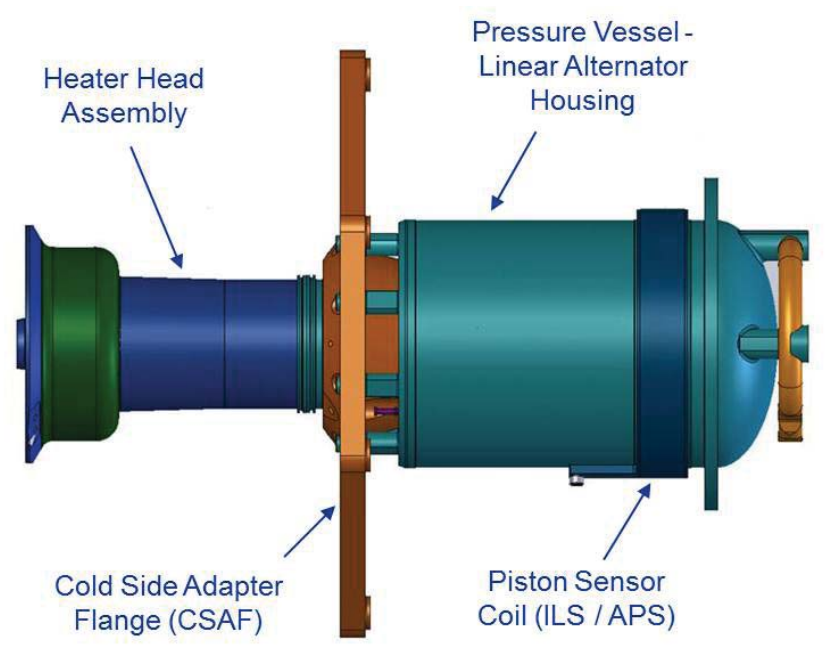

Figure 3. Dedicated ASC Clean Room at Sunpower

\section{ASC-F Flight and ASC-E3 Accomplishments}

During the parallel ASC-E3 and ASC-F builds, the integrated ASC team made numerous advancements toward flight hardware production. Highlights include:

\section{A. New Sunpower Facility and Clean Room}

In order to meet flight production requirements, Sunpower relocated to a larger facility to accommodate the growing staff and increased and more rigorous production requirements for the ASRG flight project. Sunpower completed the relocation on schedule in July 2011. The primary driver for the relocation was the flight cleanliness and Planetary Protection requirements that necessitate convertor build-up and processing in a clean room environment, Figure 4. Sunpower's facility includes dedicated lab space for convertor component processing, dedicated space for special processes, and testing capacity for a minimum of 6 convertors simultaneously.

The ASC clean room is an ISO Class 8 environment with ISO Class 5 laminar flow bench workspaces. The clean room has capacity to process up to 8 convertors simultaneously. Special processes within the clean room include convertor level inspection and processing, vacuum bake out, clean room inspection, black light inspection, specialized subassembly cleaning processes, and final assembly. The ASC-E3 Pair 2 was the first set of convertors to be processed in the clean room. The ASC-E3 Pair 3, Pair 4, and ASCF Pair 1 (for Flight Qualification Unit) have also been processed in the clean room.

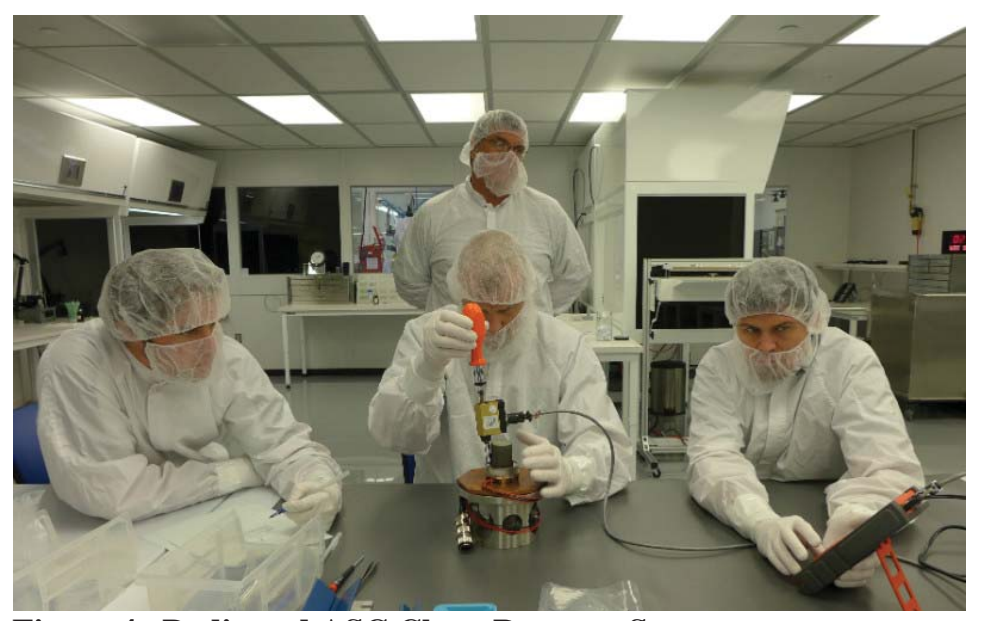

Figure 4. Dedicated ASC Clean Room at Sunpower

\section{B. Flight Production Documentation Maturity}

A strategy of the ASC-E3 and Flight parallel contracts was that a single set of flight production documentation would be used. In order to maximize lead time for ASC-E3 pair 1 and 2 pathfinders ahead of flight hardware processes, production documentation was required to be Sunpower released but was not required to be Issued (i.e. fully approved by the joint Lockheed Martin, NASA GRC, DOE Configuration Control Board) prior to use in ASC- 
E3 Pairs 1 and 2 production. However a best effort was made to use Issued documentation whenever available. In many instances, pathfinding provided by the ASC-E3 pair 1 and 2 production served as the final step in development of Flight processing and documentation refinement. ASC-E3 Pair 1 and Pair 2 production closed nearly all open issues in production documents prior to the ASC-E3 Pair 3, Pair 4 and all Flight convertor processing. Pair 3, Pair 4, and all Flight convertors were required to be processed to fully Issued documentation. ASC production documentation is divided into five categories - drawings, process documents, process specifications, test procedures, and special processes. Table 1 presents the current status of ASC documentation. All production documents have been approved with the exception of one Process Utilization List item that was in the process of being approved at the time of ASRG termination. As needed, production documentation is revised and submitted to the CCB for approval as lessons learned in production are identified.

\begin{tabular}{|l|c|c|}
\hline \multicolumn{1}{|c|}{ Document Type } & Total & Approved \\
\hline Drawings & 124 & 124 \\
\hline Process Document & 65 & 65 \\
\hline Process Specification & 27 & 27 \\
\hline Test Procedure & 37 & 37 \\
\hline Process Utilization List & 50 & 49 \\
\hline
\end{tabular}

Table 1 - ASC production documentation maturity

\section{Flight Certified Quality System}

Early in the Flight project (December 2009), Sunpower successfully passed an ISO 9001:2000 compliance audit which certified Sunpower's quality system and approved Sunpower as a Flight hardware provider. In September, 2011, after relocation to a new facility, Sunpower successfully passed a surveillance audit and recertification to ISO 9001:2000.

Key elements to building and certifying the quality system included establishing quality system governing plans and processes and developing in-house verification methods. Project level plans such as the Quality Assurance Program Plan, Configuration Management Plan, Quality Assurance Inspection Plan, Software Management Plan, Contamination Control Plan, and Verification Plan were project-level deliverables that were reviewed and approved by the customer and set the project requirements for Sunpower. Key processes established include nonconforming material control, corrective and preventative action system, configuration management, and process qualification via the Process Utilization List. In-house verification methods included incoming material and product inspection, certified inspection of workmanship standards, and inspection to meet cleanliness requirements.

\section{Regenerator Production Capabilities}

Sunpower designers had worked with a GRC materials specialist to develop the high-temperature, oxidationresistant, high porosity regenerators used in the ASC design. Once production methods were established and hardware demonstrated, it was desired to transfer regenerator production responsibility to Sunpower. This was done slowly in step-wise fashion including training and review of resultant regenerators produced at Sunpower. Transferring production to Sunpower was viewed as a minimal risk and a necessary step for securing future convertor production as the production process was developed in a research laboratory at GRC not intended for high volume flight production. Sunpower established a duplication of GRC's regenerator production capabilities in the new facility and successfully produced all ASC-E3 and ASC-F regenerators.

\section{E. New Mechanical Joint for CSAF}

During production of the ASC-E3, technical issues were identified related to bonding of the Cold Side Adapter Flange (CSAF), Figure 5, that provides structural support and provides heat rejection from the ASC to the generator housing. A mechanical press fit joint with supplemental fasteners between the CSAF and the "transition assembly" hub of the ASC was established to replace the metallurgical joint. The new mechanical joint was demonstrated to meet all performance and structural requirements through component thermal vacuum testing, convertor operation, and qualification-level vibration testing, so it was adopted on the E3/ F design.

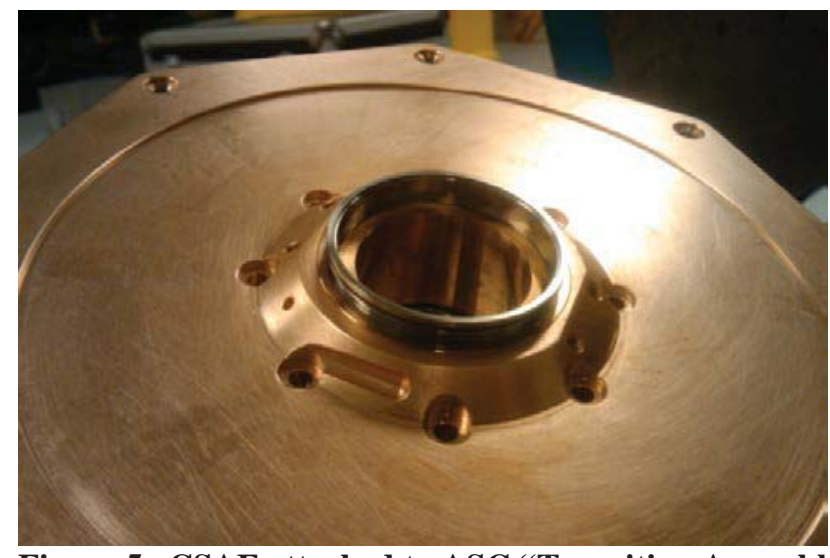

Figure 5. CSAF attached to ASC "Transition Assembly" 


\section{F. Heater Head Non-destructive Inspection}

A Heater Head Technical Product Team completed the assessment of the small casting defects that may exist in the heater heads. Through material tests, component tests, structural modeling and analysis, and multiple high level vibration tests, the team concluded that the non-destructive evaluation of each finished heater head using Microfocus X-Ray computed tomography and high temperature helium leak testing is sufficient to screen for any critical defects, ensuring all heater heads used on ASCs meet design requirements. ${ }^{6}$

\section{G. Cylinder Assembly Improvement}

Production issues were encountered for the critical cylinder assemblies that define the bore in which the piston and displacer reciprocate. The issue was resolved over the course of several months by a dedicated working group leading to improvements in heat treatment of the cylinder stock material, improved dimensional control at the component and assembly level, and improved process for bonding the assembly. The issue was resolved and convertor production with acceptable cylinders continues. In parallel, trials have shown a significant increase in production yield and manufacturability when implementing the recommendations of the working group.

\section{H. Improvements in Sunpower ASC Operational Testing}

Many significant improvements were made in ASC testing throughout the ASC-E3 and ASC-F projects. Improvements were developed by the testing team led by NASA GRC personnel that included Sunpower and Lockheed Martin staff in response to project needs for higher fidelity test data and test standardization to minimize inaccuracies and miscommunication. The team included testing, engineering, manufacturing, technician, and quality disciplines. Standardizing test methodologies and terminology and increasing accuracy and repeatability of tests at all locations provided significant benefits as discussed below.

\section{Common Performance Hardware -} An improvement in testing ASC convertors is the adoption of a new "common performance hardware" design that is used for all performance verification and performance mapping tests at Sunpower and GRC. The common performance hardware includes the intergrated insulation, electric heaters, thermocouples, and structural support for the test. It minimizes overall heat leaks, and reduces variability in test data based on test setup tear-downs and test location. The use of the setup also allows for more accurate and repeatable modeling of the net heat input to the convertor, a key parameter to establish the performance of each ASC. ${ }^{7}$ Additionally, each ASC-E3 is delivered installed in the common performance hardware allowing GRC to perform independent performance verification tests using the same physical test configuration as was tested at Sunpower prior to delivery, further minimizing data variability. The test configuration for ASCE3 Pair 1 as assembled at Sunpower, then
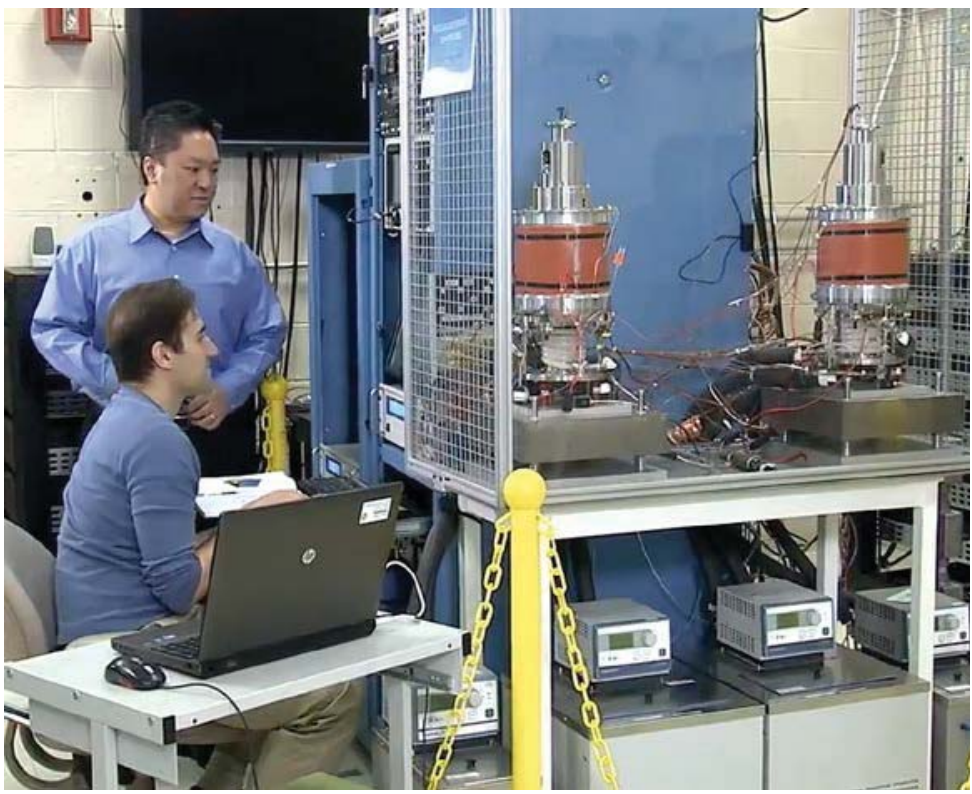

Figure 6. ASC-E3 Pair 1 (\#1 \& \#2) in individual Common Performanc Hardware under vertical performance testing at GRC's SRL installed at GRC is shown in Figure 6.

2. Test Software - Primarily developed by the NASA GRC test team, the Labview test software employed at GRC and Sunpower has been standardized and placed under configuration control. The program is written specifically for ASC testing with control screens and graphical interface options that are tailored to the user location but available for use by all operators. For example, Sunpower tests are focused on some different indicators and data since the convertors spend most of their processing in a non-hermetic form. Thus, Sunpower uses a tailored 
control screen. For purposes of troubleshooting and communication, the same screen is available on all NASA GRC test racks. Additinally, the Sunpower data capture rates have been improved in the software to allow more detailed analysis of test data at the 2-second sampling rate and kilohertz rate for some parameters.

3. Unattended Convertor Operation - A capability added to the Sunpower test rack that has made a significant impact is unattended operation. The controls and safeties used for unattended operation were developed over years of continuous extended operation testing across many different convertors at GRC. In addition to the software controls, GRC provided Sunpower with Failsafe Protection Circuits. With unattended operation, convertors can test 24-7 with alarms programmed to safely shut down convertors if their performance is outside of programmed allowables. With unattended operation, Sunpower's production cycles can be reduced by eliminating some of the warm-up and cool-down cycles during testing, each of which can span 1-2 hours per day.

4. Horizontal Operation with Clocking - While prior convertor production testing included limited horizontal operation, and some post-delivery testing at GRC was done horizontally, in order to improve characterization of the ASCs in multiple orientations, the test team developed a fixture which allowed convertors in non-hermetic production stages to be operated horizontally in multiple clockings. On the ASC-E3 Pair 3, a newly configured Shakedown test sequence was implemented that allowed testing to occur in four clocked, horizontal positions at all reference test conditions without breaking configuration and without stopping the convertor to change orientation.

\section{J. First Operation of ASC-F Flight Convertors}

In June 2013, Sunpower operated for the first time an ASC-F that was built to the rigors of flight production and quality requirements. The initial pair of ASC-F was allocated for integration on the ASRG Qualification Unit that would have been fueled and subjected to rigorous system level tests. These initial flight units were undergoing shakedown testing when flight contract termination stopped all work on them, and the convertors were secured in storage. The convertors are being transferred to the GRC ASC contract although no decisions have been made yet in terms of what will be done with these units.

\section{K. Delivery of ASC-E3 Pair 1 and Pair 2}

In November 2012, Sunpower completed and delivered to GRC the first ASC-E3 "pathfinder” pair. Figure 7 shows unit \#2 while it was still early in its production stages, prior to heater head and PV welds. As expected, there were many lessons-learned and production issues uncovered that were resolved, reducing risk to the production of later flight convertors. ASC-E3 Pair 1 generally followed flight production requirements except for assembly in the clean room. ASC-E3 Pair 2 convertors were the pathfinders for clean room production. While it is typical for pairs to have parallel production throughout, Pair 2 did not and as a result, ASC-E3 \#4 was delivered to GRC in August 2013 and E3 \#3 and was delivered in November 2013.

All ASC-E3 Pair 1 and Pair 2 convertors met performance specification at Sunpower and later at GRC during independent verification tests. E3 Pair 1 was configured in a dual-opposed configuration, completed supporting ASRG controller testing at Lockheed Martin Coherent Technologies. Pair 1 has been returned to GRC and is currently being integrated into the ASRG Engineering Unit \#2 generator for system level testing.

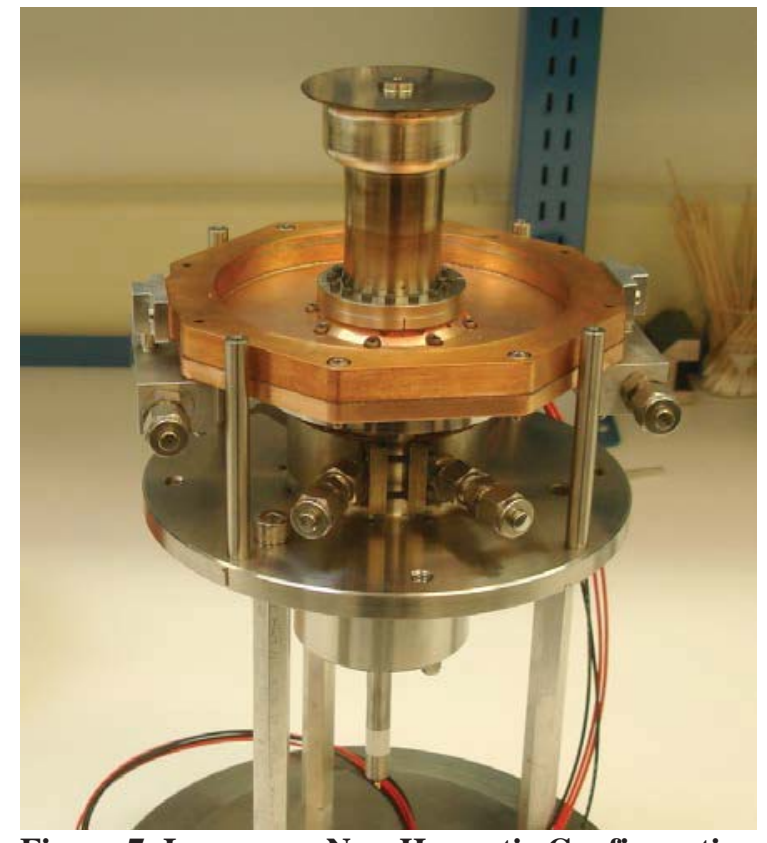

Figure 7. In-process Non-Hermetic Configuration ASC-E3 \#2

\section{GRC ASC Convertor Testing}

GRC's Stirling Research Laboratory (SRL) was established in 1999 and has expanded as additional convertors became available and additional space was required. The primary function of the SRL is to test Stirling convertors and generators, typically in unattended extended operating mode. The SRL has developed test capabilities and 
methods that allow safe continuous operation of high value hardware that provides autonomous safe shutdowns if any faults are detected. The SRL also has a dedicated thermal vacuum facility that allows operation of Stirling systems in a relevant environment. Design, build-up, and maintenance of the control systems, data systems, longlife electric heat sources, and ancillary facility support systems are also SRL responsibilities.

Establishing life and reliability of the ASC technology has been imperative. Many activities including modeling, structural analysis, metallic and organic material evaluations, component testing, convertor vibration and durability testing, and reliability modeling have been completed by GRC to assess the reliability and margins of the ASC design. The continuous extended operation of ASC convertors and generators in the SRL plays a central role in establishing the reliability of Stirling systems. Table 2 shows the accumulated operating hours for select ASC convertors at GRC. ASC-0 \#3, an early laboratory demonstration convertor is the unit leader for accumulated operating time with almost 45,000 hours (over 5 years). ASC-E3 \#4 is the flight-like convertor that has nearly 5,000 hours. In total, the cumulative operating hours for All ASC convertors at GRC is Over 316,000. Meanwhile, additional test racks and space is being prepared for testing of the additional flight-like ASC-E3 Pair 3 \& Pair 4, planned for delivery August 2014, and early 2015 respectively.

\begin{tabular}{|l|r|l|}
\hline \multicolumn{1}{|c|}{ Convertor(s) } & \multicolumn{1}{c|}{ Hours } & \multicolumn{1}{c|}{ Comment } \\
\hline ASC-0 \#3 & \multicolumn{1}{c|}{14,939} & Single ASC Leader \\
\hline & 119,728 & Total: Early Technoloy Demonstration ASCs \\
\hline ASC-E \#2 & 35,316 & Previously in ASRG EU \\
\hline ASC-E \#4 & 32,248 & Adopted some E2 changes \\
\hline ASC-E2 \#4 & 13,568 & \\
\hline ASC-E2 \#5 & 27,316 & \\
\hline & 181,451 & Total: Transition to Flight ASCs \\
\hline ASC-E3 \#1 \& \#2 & $3,109 \& 3,104$ & Preparing for ASRG EU2 installation \\
\hline ASC-E3 \#3 \& \#4 & 3,970 \& 4,939 & First units produced in Clean Room \\
\hline & 15,122 & Total: Flight pathfinder ASCs \\
\hline Total ASC & $\mathbf{3 1 6 , 3 0 1}$ & Includes all Prior ASC Units \\
\hline
\end{tabular}

Table 2. GRC ASC Operating Hours as of July 7, 2014

\section{ASC Status and Path Forward}

In late Fall 2013, the DOE initiated termination of the Lockheed Martin ASRG flight contract, driven primarily by budget constraints. As a result, Sunpower's subcontract for the flight development of ASC-F was also terminated. NASA continues to recognize the importance of high efficiency Stirling power conversion for RPS and continues investment in the technology. The Stirling effort is being reformulated currently under the Stirling Radioisotope Generator (SRG) technology development task. Immediate project objectives include completion at Sunpower of the remaining ASC-E3 Pair 3 and Pair 4 convertors. Additionally, GRC is assembling an ASRG Engineering Unit \#2 (EU2), the highest fidelity flight-like Stirling generator built to date that will integrate Sunpower's flight-like ASC-E3 Pair 1, Lockheed Martin's functionally flight-like EDU4 controller, and GRC’s aluminum flight-like housing that will enable a variety of key system level and interface evaluations. Meanwhile, SRG planning is underway to develop longer-term path forward to continue NASA Stirling RPS development. The status of flight contract termination, progress made on ASC-E3 Pair 3 and Pair 4 as well as EU2, and outlook for Stirling RPS are summarized below.

\section{A. ASC Flight Contract Termination Status}

On November 13, 2013, Sunpower received notice of termination of the ASC-F contract as a result of budgetary constraints within NASA. As of May 2014, all Sunpower flight closeout activities are complete with the exception of the final administrative closeout which is expected to occur in Fall of 2014 when Lockheed Martin's prime contract is closed.

1. Hardware transfer to ASC-E3 contract. At the direction of the integrated federal project, and in order to not adversely affect ASC-E3 production under the ongoing technology development contract with GRC, Sunpower was granted continued access to all Common Inventory hardware and all tools, fixtures, etc. that were needed for production and were previously shared by the contracts. In parallel, and in accordance with termination requirements, Sunpower began preparing a "termination inventory" of all Flight owned assets. In recognition of the ASC-E3 and Flight project dependence on Common Inventory, the integrated federal project directed DOE, Lockheed, and Sunpower to identify all hardware needed for ASC-E3 pair 3 and pair 4 production and expedite their 
transfer to the ASC-E3 project. All other lower priority flight assets at Sunpower, including the ASC-F flight convertors, are also being transferred to the GRC contract although no programmatic decisions have been made about usage of the flight convertors and subassemblies at this time.

2. Closeout of open nonconformances (NCR). At termination, there were several flight NCRs with open hardware disposition and/or preventative and corrective actions. For all NCRs relating to hardware that would be transferred to the ASC-E3 contract, the NCRs were administratively closed and then re-opened under an ASC-E3 MRB NCR. Those NCRs that would be transferred to future projects were administratively closed and added to the ASC-F lessons learned log for tracking. Any remaining NCRs were administratively closed without transfer.

\section{B. Continued ASC-E3 Production at Sunpower and ASRG EU2 Assembly at GRC}

While ASC-E3 Pair 3 was already in production at the time of ASRG termination, a result of termination was replanning for E3 Pair 4. Originally, the production sequence was for the eight flight ASC-F convertors to follow E3 Pair 3 giving flight hardware priority, followed by ASC-E3 Pair 4. With termination of the flight contract, E3 Pair 4 was accelerated and production was started earlier than planned. ASC-E3 Pair 3 convertors made excellent production progress, and they have been completed including hermetic sealing (Figure 8). They are undergoing Final Performance Testing and a Hardware Acceptance Review is planned for August 2014 with delivery to GRC anticipated about a month ahead of schedule. ASC-E3 Pair 4 front end assembly was completed and initial operation was achieved February 2014. The Pair 4 convertors are going through Shakedown Testing and have completed Heater Head weld and Pressure Vessel Sleeve Weld and delivery is expected in early 2015.

A priority for the SRG task is the completion of the ASRG EU2 utilizing the ASC-E3 Pair 1, the Lockheed Martin controller, and a flight-like aluminum Generator Housing Assembly (GHA). The high-fidelity ASRG EU2 will be used for system level performance assessment and characterizations, validation of various interfaces and system requirement, and ASC convertor extended operations within the EU2. These key system level activities will provide

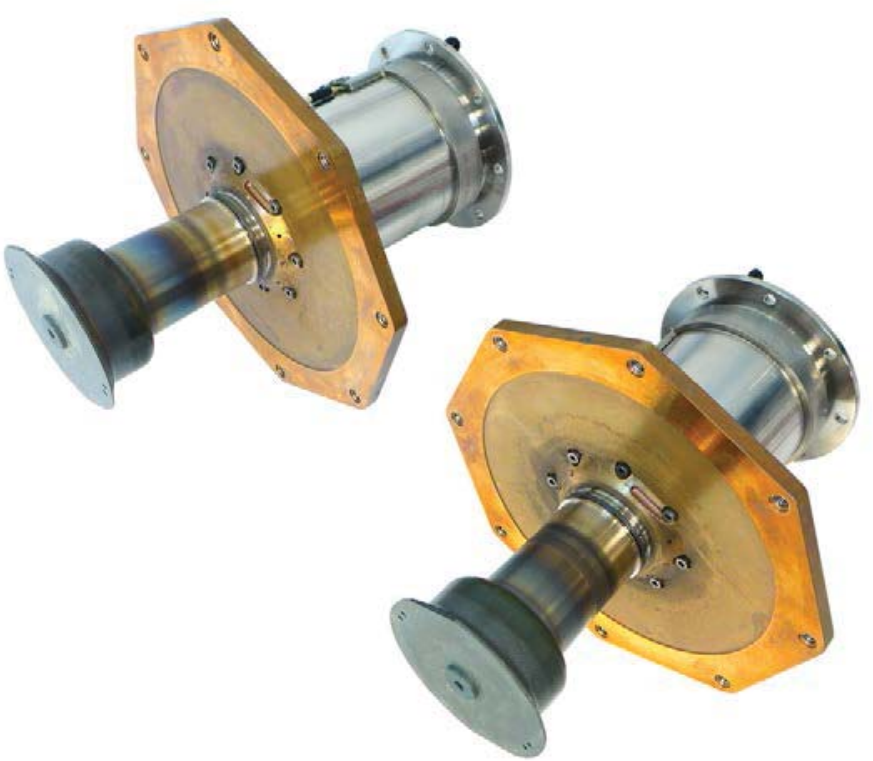

Figure 8. Completed Flight-like ASC-E3 Pair 3 Convertors data and guidance for future Stirling systems. After delivery to GRC, ASC-E3 Pair 1 convertors completed independent performance verification testing, performance mapping, and unattended operation. The units were then provided to Lockheed Martin for successful controller functional testing. ${ }^{8}$ The units have been returned to GRC, completed receipt checkout tests, and are being prepared for integration into the ASRG EU2. The ASC-E3 Pair 1 convertors have each accumulated over 3,100 hours of operation at GRC with steady flat-line performance.

GRC has awarded a contract to Lockheed Martin to complete the production and delivery of the EDU4 controller which is expected Fall 2014. Meanwhile, the GRC GHA has been completed and various practice assembly trials have been performed. The ASC-E3 Pair 1 convertors have completed dual-opposed integration with each other via the Interconnect Tube. As of this writing, ASRG EU2 assembly (Figure 9) is making good progress and plans are to operate the system, without the Lockheed Martin controller, by September 2014. Operations with the controller along with a suite of ASRG EU2 tests are planned for 2015 to $2016 .^{9}$

\section{Options for Stirling RPS Path Forward}

High efficiency Stirling power conversion for RPS systems continues to be a priority for NASA's Science Mission Directorate given the low plutonium fuel inventory in the U.S. and relatively low planned fuel production rate. In parallel with the lower 140 watt class ASRG, NASA's Space Technology Mission Directorate has also been sponsoring the development of higher power Fission Power Systems (FPS) including the development of the Sunpower $12 \mathrm{~kW}$ Stirling Power Conversion Unit (PCU). ${ }^{10}$ The PCU is planned for delivery to GRC this fall for 
integration into the fission Technology Demonstration Unit (TDU) for electrically heated system demonstration of key FPS technologies in GRC's Vacuum Facility 6 in 2015. Sunpower has developed a range of high efficiency power convertors that share common technologies and basic configuration with the $80 \mathrm{~W}$ ASC including the $35 \mathrm{~W}$ SBIR unit, a $1 \mathrm{~kW}$ convertor, and the 12 kW PCU (6 kW per dual opposed piston/alternator). Figure 10 illustrates the family of power pistons for each of these four convertors. Given the scalability of the ASC technology, the power level for any future Stirling RPS is being re-considered with options of increasing the power of the Stirling convertor based on increments of GPHS modules used with $250 \mathrm{~W}$ thermal output per module.

To help guide SMD RPS investments as well as FPS development, a Nuclear Power Assessment Study (NPAS) has been chartered to evaluate the relevant technologies for RPS and FPS, fuel availability, candidate system configurations and power levels, and reference candidate missions. The NPAS Team is expected to complete the study in Fall 2014 with recommendations for RPS and FPS path forward. In particular, the team will be assessing common technology approaches that may be applicable to both RPS and FPS systems.

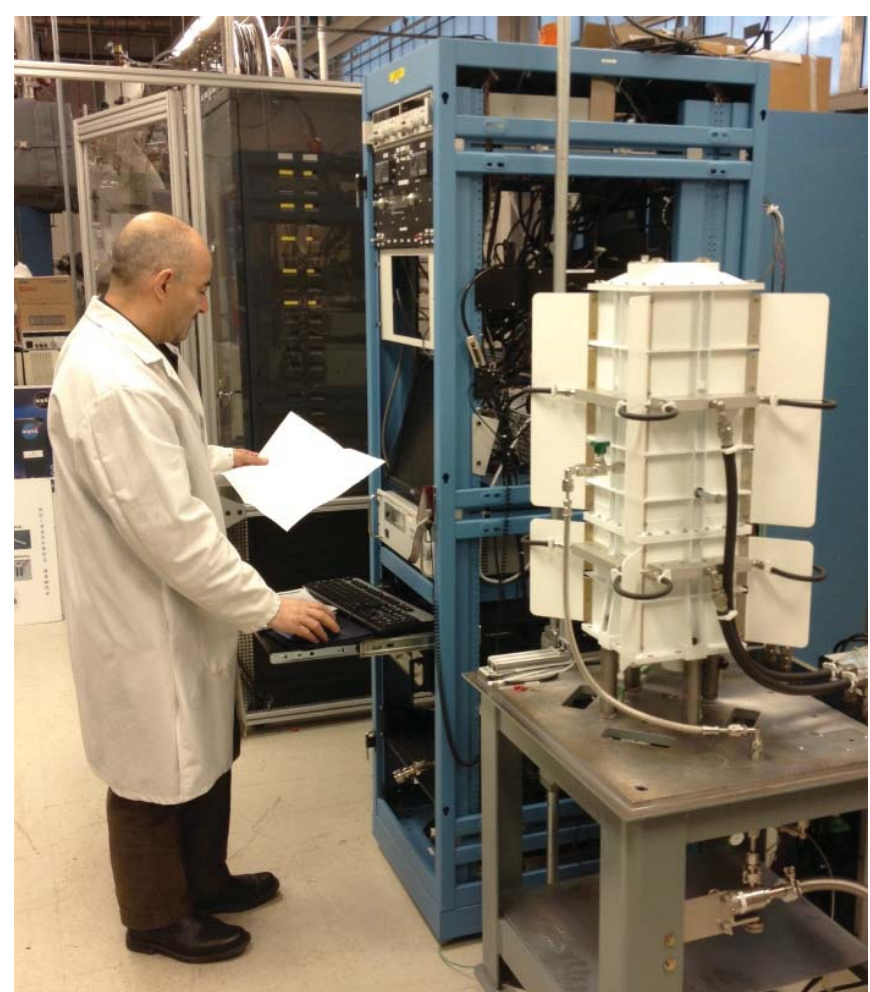

Figure 9. ASRG EU2 Flight Like Housing Fit Check \& Preparations

While no decisions on Stirling RPS path forward have been made as of this writing, programmatic interest in the high efficiency ASC technologies continues to be high given the limited fuel availability. It is anticipated that ASCE3 Pair 3 and 4 convertors will be completed and delivered, the ASRG EU 2 will complete integration and system level tests, and the GRC Stirling Research Laboratory will continue to operate the ASC convertors to expand the reliability data base. A consideration for planning is the availability of ASC flight assets including ASC-F convertors that were in production, subassemblies, and many components in bonded-storage, all of which are being transferred to the GRC ASC contract. While the ASRG flight development contract was terminated, and future Stirling RPS system designs may be different from the ASRG generator, the Stirling related technologies and engineering that have made significant advancements during the course of the ASRG project will likely continue to be applicable to future systems.

\section{Summary}

Break-through high efficiency demonstrated by Sunpower using the early ASC convertors led to the expansion of the GRC technology development project, and the adoption of the technology as part of the DOE/Lockheed Martin ASRG flight development contract. Significant progress was made by the ASRG integrated flight project team to the point that the technology was on the cusp of a launch opportunity. While not selected, the ASRG was proposed as the power system for two of the three

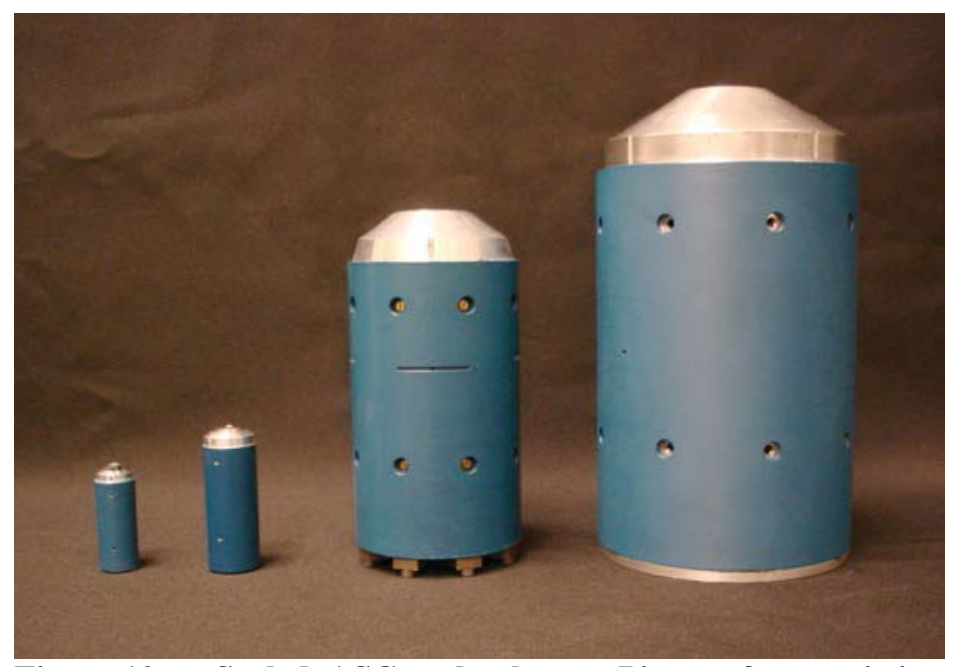

Figure 10. Scaled ASC technology - Pistons from existing Sunpower convertors, left-to-right: $35 \mathrm{~W}$ SBIR, $80 \mathrm{~W}$ ASC, 1 $\mathrm{kW}$ convertor, and $6 \mathrm{~kW}$ piston (two used for the $12 \mathrm{~kW}$ PCU) 
Discovery 12 candidate missions, Titan Mare Explorer (TiME) and Comet Hopper (CHopper). With the termination of the ASRG contract, NASA and its partners are re-evaluating technology availability, capabilities, and mission requirements in an effort to identify a path forward for sustainable, reliable, and affordable nuclear space power systems. As limited availability of plutonium-238 fuel continues to be a driver, high efficiency Stirling technology remains essential for future NASA RPS.

\section{Acknowledgments}

The work described in this paper was performed for the Science Mission Directorate (SMD) and the Radioisotope Power System (RPS) Program. The opinions expressed in this paper are those of the authors and do not necessarily reflect the views of the National Aeronautics and Space Administration. The authors thank the ASC and ASRG integrated team for the many significant contributions to advancing Stirling RPS technology.

\section{References}

${ }^{1}$ Wong, W. A., Anderson, D. J., and Tuttle, K. L., “Status of NASA’s Advanced Radioisotope Power Conversion Technology Research and Development," in the Proceedings for Space Technology and Applications International Forum (STAIF-2006), Albuquerque, NM, 2006 and also published as NASA TM-2006-214243.

${ }^{2}$ Wong, W. A., Wood, L. G, and Wilson, K., “Advanced Stirling Convertor (ASC) - From Technology Development to Future Flight Product," in the Proceedings for Space Technology and Applications International Forum (STAIF-2008), Albuquerque, NM, 2008 and also published as NASA TM-2008-215282.

${ }^{3}$ Schreiber, J. G., Thieme, L. G., and Wong, W. A., "Supporting Technology at GRC to Mitigate Risk as Stirling Power Conversion Transitions to Flight,” Sixth International Energy Conversion Engineering Conference (IECEC-2008), Cleveland, OH, 2008, AIAA and also published as NASA TM-2009-215515.

${ }^{4}$ Wong, W. A., Wilson, K., Smith, E., Collins, J., "Pathfinding the Flight Advanced Stirling Convertor Design with the ASCE3,” Tenth International Energy Conversion Engineering Conference (IECEC-2012), Atlanta, GA, 2012, AIAA, and also published as NASA TM-2014-217753.

${ }^{5}$ Collins, J., Wong, W. A., Dunlap, M. A., Smith, E., Wilson, K., "Sunpower's Dynamic Conversion to Flight with the Advanced Stirling Convertor (ASC-F),” Tenth International Energy Conversion Engineering Conference (IECEC-2012), Atlanta, GA, 2012, AIAA.

${ }^{6}$ Wilson, S. D., Wong, W. A., "NASA Glenn Research Center Support of the ASRG," Twelfth International Energy Conversion Engineering Conference (IECEC-2014), Cleveland, OH 2014, AIAA.

${ }^{7}$ Wilson, S. D., Reid, T. V., Schifer, N. A., and Briggs, M., "Overview of Heat Addition and Efficiency Predictions for an Advanced Stirling Convertor,” Ninth International Energy Conversion Engineering Conference (IECEC-2011), San Diego, CA, 2011, AIAA and also published as NASA TM-2012-217292.

${ }^{8}$ Chan, J., Wiser, J., Brown, G., Florin, D., Oriti, S., “System-Level Testing of the Advanced Stirling Radioisotope Generator Engineering Hardware,” Twelfth International Energy Conversion Engineering Conference (IECEC-2014), Cleveland, OH 2014, AIAA.

${ }^{9}$ Lewandowski, E. J., Bolotin, G. S., Oriti, S., “Test Program for Stirling Radioisotope Generator Hardware at NASA Glenn Research Center,” Twelfth International Energy Conversion Engineering Conference (IECEC-2014), Cleveland, OH 2014, AIAA.

${ }^{10}$ Stanley, J., Wood, G. J., Holliday, E., Geng, S., "Progress in the Development of a 12kWe Stirling Power Conversion Unit for Fission Power Systems,” Proceedings of the Nuclear and Emerging Technologies for Space 2013 Conference (NETS-2013), Albuquerque, NM February 25-28, 2013. 